\title{
Temperature response rates from long-term phenological records
}

\author{
Annette Menzel ${ }^{*}$, Nicole Estrella, Astrid Testka \\ Institute of Ecoclimatology, Technical University Munich, Am Hochanger 13, 85354 Freising, Germany
}

\begin{abstract}
The temperature response of long-term phenological records covering the whole 20th century was studied for 8 stations across Germany and for 3 phenophases (beginning of flowering in the horse chestnut Aesculus hippocastanum L., lilac Syringa vulgaris L., and red currant Ribes rubrum L.). Two different climate data sets were used: monthly mean temperatures for the 20th century for Germany from a Tyndall Centre data set (TYN) and a local climate data set from climate stations operated by the Deutscher Wetterdienst (German weather service, DWD) adjacent to the phenological stations. Linear regression of flowering onset and spring temperatures (March, April) revealed that, in general, a $1^{\circ} \mathrm{C}$ increase in temperature resulted in advances of flowering dates of 2.6 to $6.9 \mathrm{~d}$, with a stronger temperature response rate at climate stations with higher spring temperatures and subsequent earlier spring onset. The effects of choosing local or national mean temperatures were small. Whilst a linear relationship between spring onset dates and temperature is generally indicated, this linearity of response might not be valid over the whole temperature range. The linear response rates at single stations (DWD) decreased towards cooler stations with later onsets, and for almost all stations there was a slightly reduced response at the cooler end of the temperature range (TYN). In most cases, the response rates of flowering onset to variations in temperature (TYN) did not differ significantly between the first and the second half of the 20th century; thus, there are no indications of adaptation processes.
\end{abstract}

KEY WORDS: Response $\cdot$ Temperature $\cdot$ Temperature response rate $\cdot$ Phenology $\cdot$ Germany $\cdot$ Climate change

\section{INTRODUCTION}

Numerous studies have concurrently documented a progressively earlier start for vegetation activity in spring and, less comprehensively, a later end in autumn. Therefore, a lengthening of the growing season during the last 2 to 5 decades for the temperate and boreal zone of the northern hemisphere is clearly apparent (e.g. Walther et al. 2002, Root et al. 2003, Walther 2004). Global meta-analysis conclusively reveals a mean advance of spring events by $2.3 \mathrm{~d}$ per decade (Parmesan \& Yohe 2003). It is well known that the onset of spring and summer events, and consequently the length of the growing season, is very sensitive to climate and weather. In contrast to climatic factors influencing autumn phenology, the climate signal controlling spring and summer phenology is fairly well understood: nearly all phenophases correlate with temperatures in the preceding 1 to 3 mo (Sparks et al. 2000, Sparks \& Menzel 2002, Menzel 2003). This rela- tionship can be demonstrated in manipulative experiments (e.g. growth chambers, artificial heating of outdoor plots) or is revealed by phenological models based on temperature. The temperature response of spring and summer phenophases is most common evaluate with statistical methods, such as correlation or regression analyses, or simply by displaying onset dates vs. temperature measures. The changes currently experienced by emergence of vegetation and invertebrates may reach 6 to $8 \mathrm{~d}$ per ${ }^{\circ} \mathrm{C}$ (Sparks \& Menzel 2002, Walther et al. 2002).

Although there is little doubt that the observed changes in phenology, namely a progressively earlier onset of spring and summer phenophases in the temperate and boreal zone of the northern hemisphere, can be attributed to increasing temperatures, several questions concerning this temperature response arise.

(1) Analyses of the temperature response in phenology often use mean monthly temperature data of adjacent climate stations (e.g. Peñuelas et al. 2002, Mat- 
sumoto et al. 2003), regional or national averages (e.g. Sparks \& Carey 1995, Sparks et al. 2000, Menzel 2003) or climate reanalysis data (e.g. Chmielewski \& Rötzer 2001). However, the temperature response might depend on the spatial resolution of the climate data examined. Thus, we will first analyse whether the temperature response of 3 flowering phases at several long-running stations in Germany is different when climate data of adjacent climate stations or mean national data are utilised.

(2) There have been some indications that although there is an approximate linear relationship between spring onset dates and temperature, this relation might not be true over a wider range of temperatures (Sparks et al. 2000). We assume a broad section of linear response with smaller responses at the ends, resulting in a s-shaped (sigmoid) flowering-temperature relationship. Short records do not provide enough variation in both temperature and phenology to assess this question of linearity. Thus, secondly, by means of long-term phenological records spanning the whole of the last century we will investigate the linearity of temperature responses.

(3) As summarised in the IPCC Working Group II report, temperature changes have already affected many physical and biological systems, and the uncertainty, especially concerning phenology and growing season changes, is relatively low (IPCC 2001). In contrast, major gaps exist about evidence of adaptation processes. Thus, thirdly, we will evaluate whether the temperature response in separated time periods during the 20th century is diverging, which might be a clue for adaptation.

\section{MATERIALS AND METHODS}

\subsection{Phenological data}

From the data set of long-term phenological time series covering the 20th century (1900 to 2000) in Germany (A. Testka unpubl. data), we selected 3 phenophases: the beginning of flowering of the horse chestnut Aesculus hippocastanum L., lilac Syringa vulgaris L., and red currant Ribes rubrum L. These phases were selected since they were available at a number of stations with long-term data series. The observations were recorded at 8 different sites within the network of the German Weather Service (Deutscher Wetterdienst, DWD) (see Fig. 1). The phenological observations compiled originated from different sources and networks (Menzel \& Testka 2002, A. Testka unpubl. data): observations within one of the first (European) phenological networks, published by Ihne (1883 to 1941), were extracted from the historical phenological database of the DWD. Observational records for 1936 to 1944 were

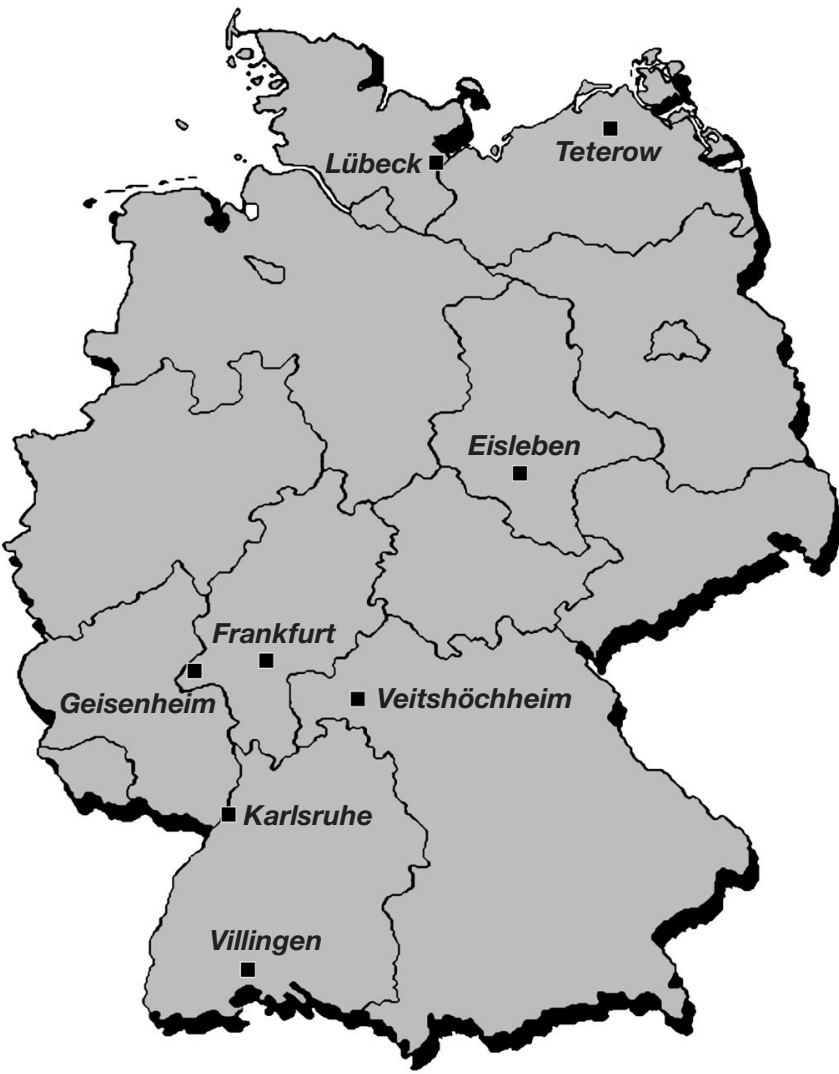

Fig. 1. Locations of the 8 long-term phenological stations in Germany

digitised from Schnelle \& Witterstein (1952). Post World War II data (1945 to 1952) in the former West Germany were extracted from the corresponding meteorological yearbooks (DWD 1949-1952, 1960); 1947 to 1956 data for the former East Germany were taken from Seyfert $(1957,1960,1961)$ and some original record sheets. From 1951 onwards, the observations originate from the current phenological network of DWD including 1961 to 1990 data from the Meteorological and Hydrological Service of the former East Germany. All phenological data (whether digital or hard copy) were kindly provided by the DWD. Data were checked for plausibility (correlation with neighbouring phases, appropriate seasonal order), and obvious errors (e.g. wrong month) and were corrected when necessary. Smaller gaps in the records (between 1 and $15 \%$ of all records) were filled by correlation with observations at adjacent stations or observations of preceding or following phases at the same station when the correlation coefficient was greater than 0.55 . Following this process only a few years (some in the 1920s and 1930s, but mostly after World War II) had missing values. The stations at Geisenheim, Teterow and Lübeck, in particular, provide nearly complete time series of the 20th century. 


\subsection{Climate data}

For some of the phenological stations (see Fig. 1), the temperature data recorded at the adjacent climate stations provided a complete coverage for the 20th century (Karlsruhe; Hamburg Fuhlsbüttel at ca. $50 \mathrm{~km}$ distance from the phenological station at Lübeck) or partial coverage (1935 to 2000 Geisenheim; 1936 to 2000 Bad Dürnheim at $10 \mathrm{~km}$ from Villingen). The 1900 to 2000 climate data for the phenological station of Eisleben had to be built up from 3 different locations of corresponding climate stations; thus, these temperature time series can not be regarded as homogenous. Further non-homogeneity may stem from change of observing time, change of instruments/exposition or sometimes from observers. Local climate station information is hereinafter referred to as DWD.

Temperature data for the other phenological stations were not suitable either due to a combination of different relocated climate stations (Frankfurt, Veitshöchheim) or due to their distance from the phenological station (Teterow, nearest climate station Schwerin at ca. $70 \mathrm{~km}$ distance).

Monthly mean temperatures for each calendar month for the 20th century for Germany (1901 to 2000, country summary) have been taken from the Tyndall
Centre (TYN CY 1.1) data set (Mitchell et al. 2004, www.cru.uea.ac.uk/ timm/cty/obs/TYN_CY_1_1_text. html; see also Mitchell \& Jones 2005). This data set is hereinafter referred to as TYN.

\subsection{Methods}

Previous studies have shown that for the onset of spring activity the temperatures of the preceding spring months are decisive (Sparks et al. 2000, Matsumoto et al. 2003, Menzel 2003). For the spring phases analysed in this paper, stepwise linear regressions with mean monthly temperatures (proc stepwise, SAS statistical package) revealed the months March and April, and often February, as months with the highest correlation coefficients. In order to homogenise the analyses here, we always tested the relationships between the onset of the 3 spring flowering phases and mean monthly temperatures of March and April, although a slightly different combination of months could have resulted in a minor increase of variation explained $\left(R^{2}\right)$. For all 3 questions (see 'Introduction'), the onset of floweringspring temperature relationships were assessed by scatter plots, linear regression models and LOWESS smoothing (LOcally-WEighted Scatterplot Smoother).

Table 1. Aesculus hippocastanum, Syringa vulgaris and Ribes rubrum. Results of linear regressions between flowering onsets of horse chestnut, lilac and red currant and mean monthly March/April temperatures. TYN: Tyndall Centre (www.cru.uea.ac.uk/ timm/cty/obs/TYN_CY_1_1_text.html, Mitchell et al. 2004); DWD: Deutscher Wetterdienst (German weather service) data taken from climate stations adjacent to phenological stations; DOY: day of the year, mean onset date during 1900 to 2000 , $\left(\right.$ day $\left./{ }^{\circ} \mathrm{C}\right)$; $\mathrm{n}$ : number of observations; $\mathrm{R}^{2}$ : variation explained; TYN-DWD: difference between TYN and DWD. All regressions are significant $(\mathrm{p}<0.0001)$

\begin{tabular}{|c|c|c|c|c|c|c|c|c|c|c|c|c|c|}
\hline \multirow[t]{2}{*}{ Species } & \multirow[t]{2}{*}{ Station } & \multirow{2}{*}{$\begin{array}{c}\text { Date } \\
\text { (d.mo) }\end{array}$} & \multirow[t]{2}{*}{ DOY } & \multicolumn{4}{|c|}{$\longrightarrow$ TYN } & \multicolumn{4}{|c|}{$\longrightarrow$ DWD } & \multicolumn{2}{|c|}{ TYN-DWD } \\
\hline & & & & Slope & $\mathrm{SE}$ & $\mathrm{n}$ & $\mathrm{R}^{2}$ & Slope & $\mathrm{SE}$ & $\mathrm{n}$ & $\mathrm{R}^{2}$ & Slope & $\mathrm{R}^{2}$ \\
\hline \multirow{8}{*}{$\begin{array}{l}\text { Horse } \\
\text { chestnut }\end{array}$} & Karlsruhe & 27.04 & 117 & -4.84 & 0.59 & 81 & 0.45 & -5.19 & 0.66 & 81 & 0.46 & 0.35 & -0.01 \\
\hline & Geisenheim & 28.04 & 118 & -4.77 & 0.44 & 97 & 0.55 & -5.53 & 0.69 & 63 & 0.57 & 0.76 & -0.03 \\
\hline & Frankfurt & 29.04 & 119 & -4.81 & 0.47 & 86 & 0.55 & & & & & & \\
\hline & Veitshöchheim & 06.05 & 126 & -4.75 & 0.58 & 75 & 0.47 & & & & & & \\
\hline & Eisleben & 09.05 & 129 & -4.58 & 0.46 & 81 & 0.56 & -4.06 & 0.44 & 82 & 0.54 & -0.52 & 0.01 \\
\hline & Lübeck & 13.05 & 133 & -3.49 & 0.49 & 95 & 0.35 & -3.10 & 0.49 & 95 & 0.32 & -0.38 & 0.02 \\
\hline & Teterow & 15.05 & 135 & -4.04 & 0.50 & 93 & 0.42 & & & & & & \\
\hline & Villingen & 21.05 & 141 & -2.55 & 0.70 & 78 & 0.15 & -3.12 & 0.81 & 52 & 0.20 & 0.57 & -0.05 \\
\hline \multirow[t]{8}{*}{ Lilac } & Karlsruhe & 25.04 & 115 & -5.89 & 0.60 & 81 & 0.55 & -5.90 & 0.71 & 81 & 0.51 & 0.01 & 0.04 \\
\hline & Geisenheim & 25.04 & 115 & -5.03 & 0.63 & 97 & 0.40 & -5.68 & 0.94 & 63 & 0.45 & 0.66 & -0.06 \\
\hline & Frankfurt & 29.04 & 119 & -4.65 & 0.45 & 86 & 0.56 & & & & & & \\
\hline & Veitshöchheim & 01.05 & 121 & -4.57 & 0.48 & 75 & 0.55 & & & & & & \\
\hline & Eisleben & 07.05 & 127 & -5.37 & 0.43 & 81 & 0.67 & -4.57 & 0.44 & 82 & 0.58 & -0.80 & 0.08 \\
\hline & Lübeck & 15.05 & 135 & -4.58 & 0.53 & 95 & 0.44 & -4.46 & 0.50 & 95 & 0.39 & -0.12 & 0.05 \\
\hline & Teterow & 16.05 & 136 & -4.72 & 0.48 & 93 & 0.51 & & & & & & \\
\hline & Villingen & 20.05 & 140 & -3.07 & 0.63 & 78 & 0.24 & -3.60 & 0.72 & 52 & 0.26 & 0.53 & -0.02 \\
\hline \multirow{8}{*}{$\begin{array}{l}\text { Red } \\
\text { currant }\end{array}$} & Geisenheim & 09.04 & 99 & -5.15 & 0.57 & 97 & 0.46 & -6.34 & 0.81 & 63 & 0.44 & 1.18 & 0.02 \\
\hline & Karlsruhe & 09.04 & 99 & -5.04 & 0.63 & 81 & 0.44 & -5.21 & 0.72 & 81 & 0.44 & 0.17 & 0.00 \\
\hline & Frankfurt & 10.04 & 100 & -4.58 & 0.69 & 86 & 0.34 & & & & & & \\
\hline & Veitshöchheim & 11.04 & 101 & -5.08 & 0.56 & 75 & 0.52 & & & & & & \\
\hline & Eisleben & 20.04 & 110 & -6.90 & 0.62 & 81 & 0.61 & -6.30 & 0.57 & 82 & 0.51 & -0.60 & 0.09 \\
\hline & Lübeck & 24.04 & 114 & -5.13 & 0.63 & 95 & 0.41 & -5.02 & 0.59 & 95 & 0.32 & -0.11 & 0.10 \\
\hline & Teterow & 26.04 & 116 & -5.38 & 0.63 & 93 & 0.44 & & & & & & \\
\hline & Villingen & 02.05 & 122 & -4.46 & 0.81 & 78 & 0.28 & -5.31 & 0.85 & 52 & 0.31 & 0.85 & -0.02 \\
\hline
\end{tabular}



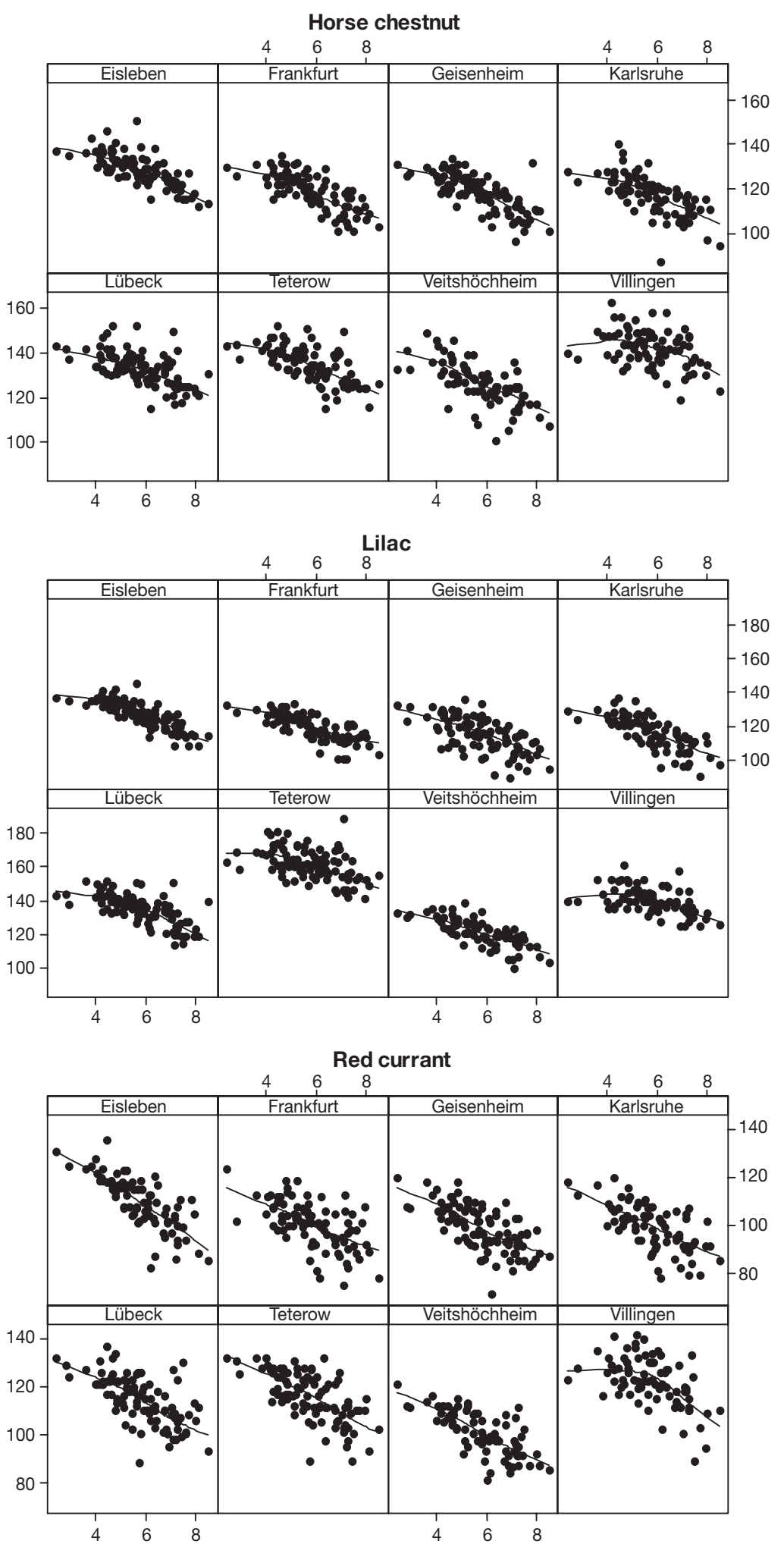

Fig. 2. Aesculus hippocastanum, Syringa vulgaris and Ribes rubrum. Beginning of flowering in horse chestnut, lilac and red currant ( $y$-axis, days since January 1), vs. monthly mean air temperatures in March/April $\left(t 34, x\right.$-axis, $\left.{ }^{\circ} \mathrm{C}\right)$ at 8 different stations in Germany (data taken from TYN CY 1.1 data set, Mitchell et al. 2004, ww.cru.uea.ac.uk/ timm/cty/obs/ TYN_CY_1_1_text.html)

\section{RESULTS}

\subsection{Variation of temperature response with climate data sets}

The responses of the onset of flowering to variations in temperature (both TYN and DWD climate data sets) are displayed in Figs. 2 \& 3; the results of fitting linear regressions are summarised in Table 1.

In general, all phases at all stations, regardless of the climate data set used, revealed the well known relationship of higher spring temperature resulting in earlier flowering onset. In the scatter plots of flowering vs. TYN (Fig. 2), the mean spring onset dates of the stations followed the climate differentiation of regions. Mean flowering dates differed by almost 1 mo between the phenological stations with earliest onset dates (Karlsruhe, Geisenheim) and the latest (Villingen). In the scatter plots of onset vs. DWD (Fig. 3), the data points arranged on both the $x$ - and the $y$-axis followed the local climate (temperature) conditions and their biological mirror (onset of flowering).

In general, a $1^{\circ} \mathrm{C}$ increase in temperature resulted in advances of flowering dates of 2.6 (flowering of horse chestnut at Villingen) to $6.9 \mathrm{~d}$ (flowering of red currant at Eisleben). The percentage of variation explained by linear regressions covers a large range between $15 \%$ (horse chestnut, Villingen) and 67\% (lilac, Eisleben) (Table 1). For horse chestnut and lilac, the response to TYN was mostly more pronounced for stations with earlier means (mean date vs. slope: horse chestnut, $\mathrm{r}=0.87, \mathrm{R}^{2}=76 \%$; lilac, $\mathrm{r}=0.68, \mathrm{R}^{2}=46 \%$ ), this pattern was also visible for the regression with DWD. Response rates of flowering of red currant did not display this stronger temperature response at earlier stations (mean date vs. slope: $r=-0.04, R^{2}=0 \%$ ).

There was a maximum of $10 \%$ difference between the percentages of variation explained $\left(\mathrm{R}^{2}\right)$ for TYN and $\mathrm{DWD}$; often the higher values were reached by TYN. At Eisleben and Lübeck the temperature response determined for DWD was lower than for TYN; for Geisenheim, Karlsruhe and Villingen the response to local climate was more pronounced. However, the maximum difference was $1.2 \mathrm{~d}$ per ${ }^{\circ} \mathrm{C}$. The effect of choosing local or national mean temperatures was small. 

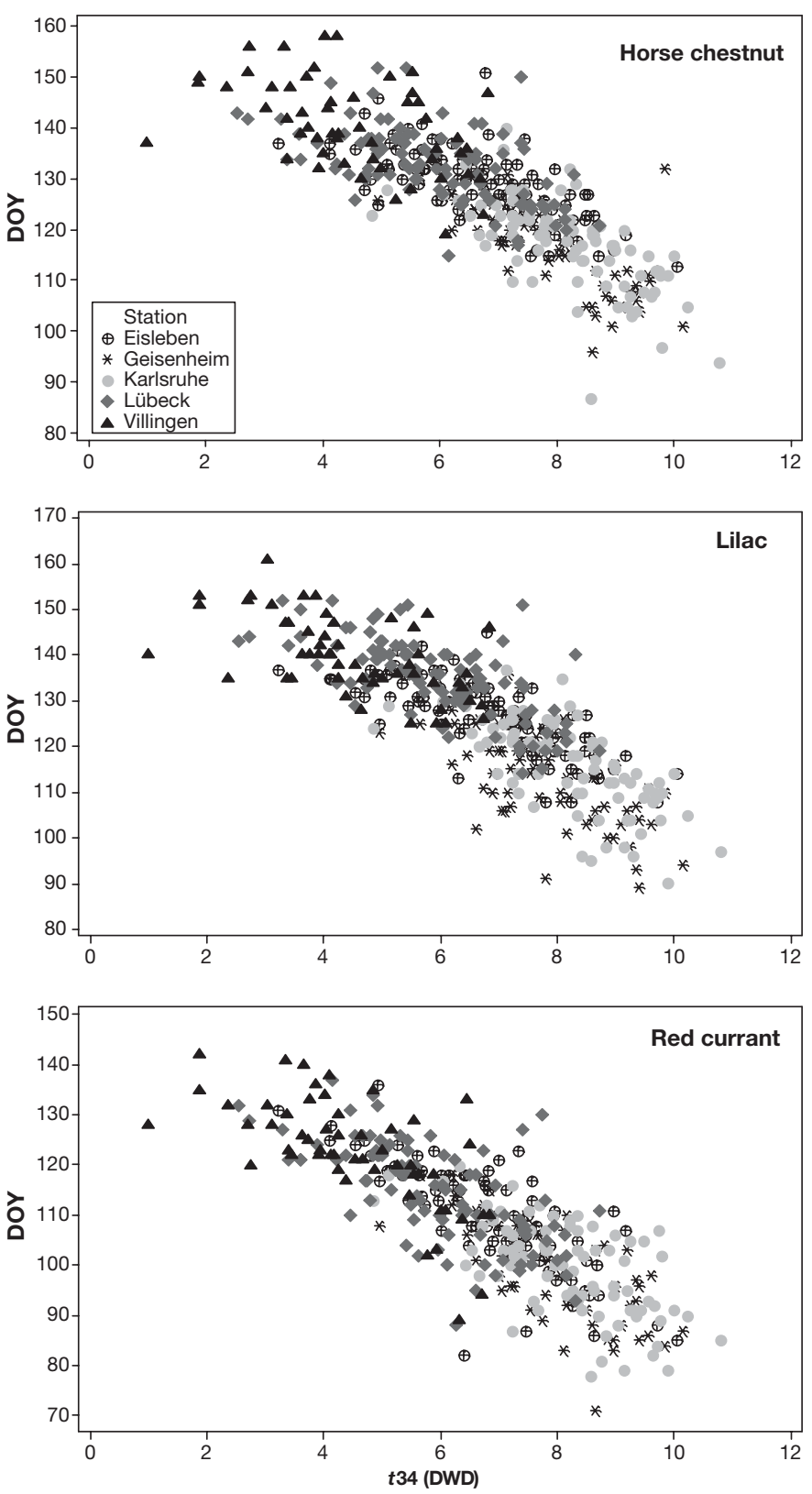

Fig. 3. Aesculus hippocastanum, Syringa vulgaris, and Ribes rubrum. Beginning of flowering in horse chestnut, lilac and red currant vs. monthly mean air temperatures in March/ April ( $t 34)$ at 5 different stations in Germany (DWD temperature data from adjacent climate stations of the German Weather Service). DOY: day of the year

\subsection{Linearity of temperature response}

The LOWESS smoothing (TYN) (Fig. 2) reveals almost linear relationships. At almost all stations the response is slightly flattened at the cooler edge of the temperature range. Out of 24 examples, only 6 do not display this pattern: flowering of horse chestnut at Veitshöchheim, lilac at Teterow and Veitshöchheim, and red currant at Eisleben, Lübeck and Teterow. In particular, for the coldest station in the data set, Villingen, a non-linear relationship is displayed by the LOWESS smoothing.

However, at the warmer end of the temperature range, the hypothesized reduced temperature response, which would finally result in the hypothesised s-shaped (sigmoid) flowering-temperature relationship, is not as expected (e.g. only for horse chestnut at Geisenheim and Lübeck, lilac at Eisleben and Frankfurt, and red currant at Geisenheim and Teterow); for all other cases this pattern is not apparent.

The relationship of onset dates vs. DWD spring temperature is almost linear for each station separately and all stations together (Fig. 3). Here, as for the TYN response discussed above, the linear response rates at single stations are lower in cooler stations with later onsets (see Table 1), but not in warmer stations with earlier onset; thus, an increasing non-linearity of the response is only apparent for the colder end.

\subsection{Variation of temperature response with time}

In Fig. 4 the LOWESS curves for the responses of the onset of flowering to variations in temperature (TYN) are displayed for 2 different time periods: 1900 to 1950 (I) and 1951 to 2000 (II); the slopes and the standard error of the slopes of the corresponding linear regressions are summarised in Fig. 5. The regressions at all stations and periods are significant $(p<0.001)$ except those in the 1900 to 1950 period at Villingen, which are consequently not further analysed (Fig. 5). In most cases, there are no significant differences between the slopes in the first and the second half of the 20th century. Rare relevant differences show both larger responses in the first half (twice) and in the second half of the century (four times). Slightly smaller, but not significantly different, responses (in days per ${ }^{\circ} \mathrm{C}$ ) are often revealed in the second half of the century. The results when comparing the LOWESS fits are quite similar. For flowering of horse chestnut and lilac there are almost no differences. For red currant, it seems that similar mean March/April temperatures have resulted in earlier flowering dates in the first half than in the second half of the 20th century. This might be connected with a possible change in cultivars planted.

\section{DISCUSSION AND CONCLUSIONS}

Climatological studies have revealed that the spatial correlation of air temperature is relatively high. In Germany, Schönwiese et al. (1998) demonstrated for the reference climate station Frankfurt a. Main that for 

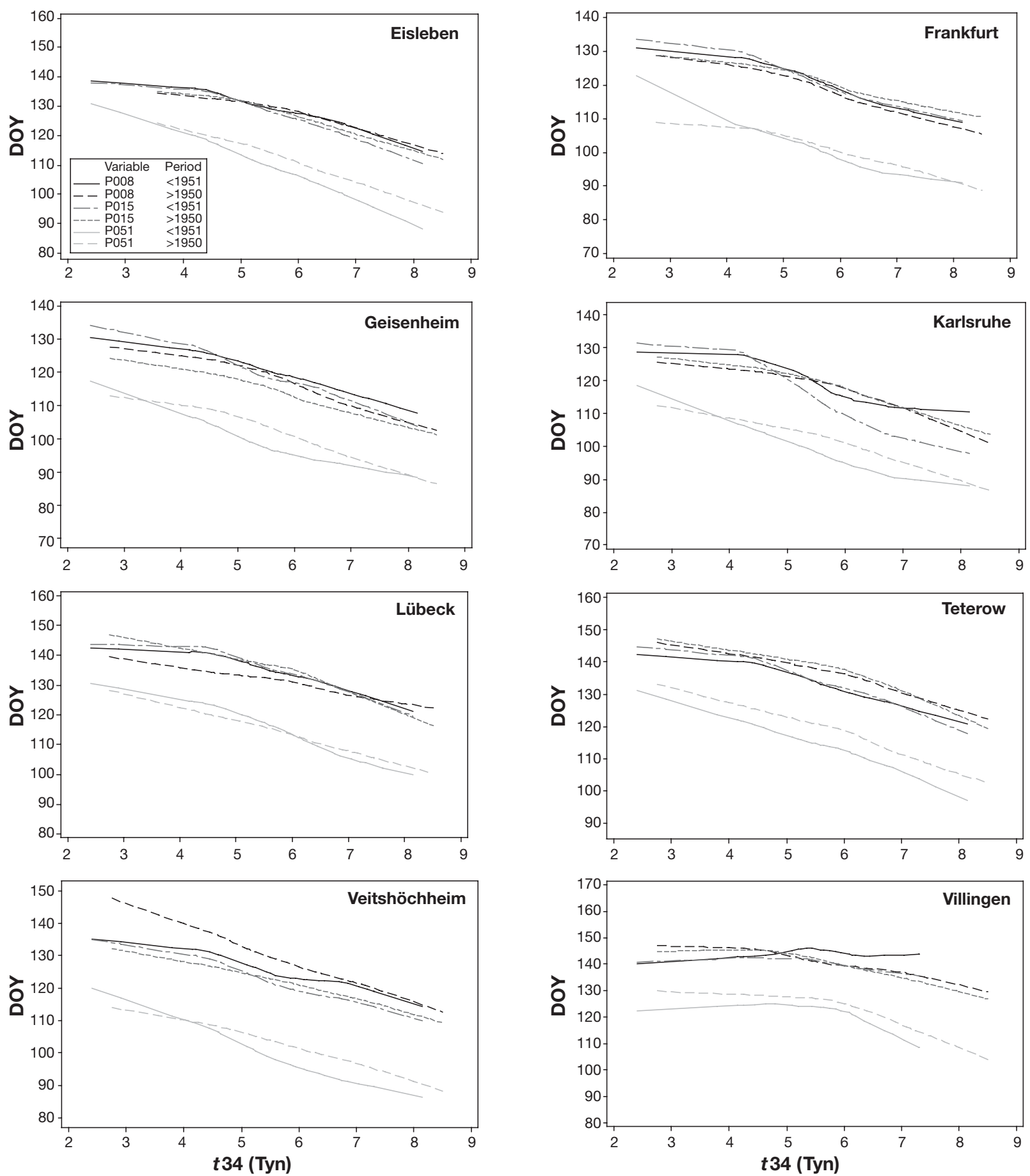

Fig. 4. Aesculus hippocastanum, Syringa vulgaris and Ribes rubrum. LOWESS fits for beginning of flowering in horse chesnut (P008), lilac (P015) and red currant (P051) vs. monthly mean air temperatures in March/April ( $t 34$ TYN) for 2 different time periods (1900 to 1950 and 1951 to 2000). DOY: day of the year

winter and annual values the correlation coefficients between Frankfurt and 95 other stations were mostly above 0.8, even for stations $800 \mathrm{~km}$ distant. As expected, the spatial representativeness of summer temperature was lower (on average 0.9 for $100 \mathrm{~km}$ dropping to 0.5 for $800 \mathrm{~km}$ distant). This high spatial coherence of temperature might be the reason why the choice of temperature data leads to relatively small differences in the computed temperature responses (for linear regressions a maximum difference in slope of $1.2 \mathrm{~d}$ per ${ }^{\circ} \mathrm{C}$, a maximum difference in $\mathrm{R}^{2}$ of $10 \%$ ). This means that the primary relationship between 

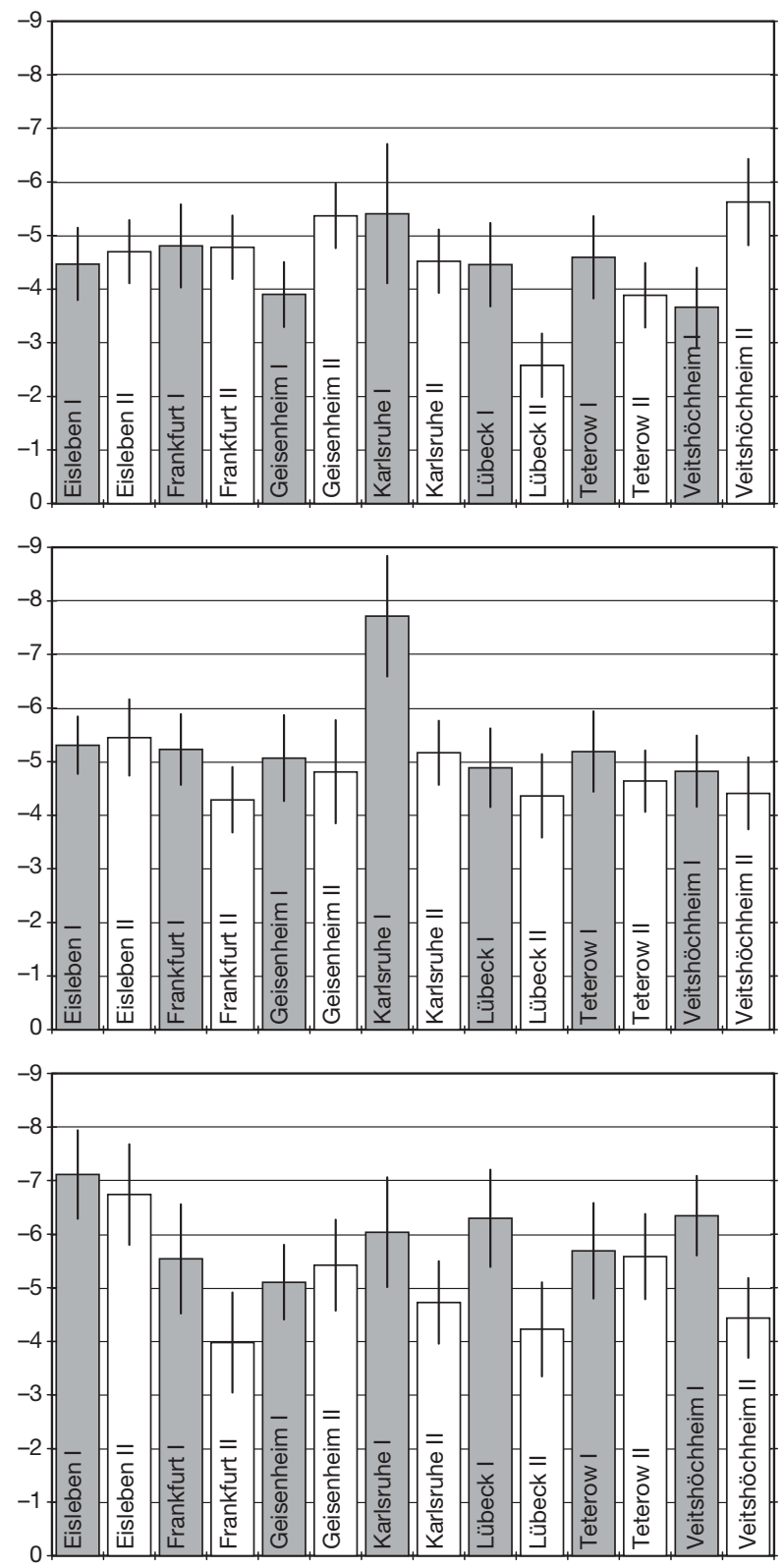

Fig. 5. Aesculus hippocastanum, Syringa vulgaris and Ribes rubrum. Temperature response rates for 2 different time periods (I: 1900 to 1950; II: 1951 to 2000). White and grey bars represent the slopes of linear regressions in March/April $( \pm \mathrm{SE})\left(y\right.$-axis, days per $\left.{ }^{\circ} \mathrm{C}\right)$ (upper panel: horse chestnut; middle panel: lilac; lower panel: red currant). All regressions are significant $(\mathrm{p}<0.001)$

onset of phenological phases and mean spring temperatures is consistent even for different temperature data sets. One has to take into account that the plant observed will be at a certain distance from the local climate station, will most likely experience other microclimates and be exposed to a range of plant body temperature rather than air temperature measured in shade at $2 \mathrm{~m}$. Thus, depending on the phenological station, the temperature response was slightly higher with either the national or the local climate data set. There is a need for further research to determine whether it is really a fact that the responses to local climate station data, compared to national mean temperatures, seem to be more pronounced in warmer regions (e.g. Karlsruhe, Geisenheim) and less so in colder regions (e.g. Eisleben, Lübeck, see Table 1).

The hypothesis that the temperature response of phenological spring phases is not linear over the whole range of spring temperatures is quite reasonable. Relatively cold weather in spring may delay the onset of spring phenophases over a large range of temperatures. Nevertheless, the plant might finally react to day length in order not to 'miss too much of the growing season'. In addition, temperatures below a certain threshold (e.g. $5^{\circ} \mathrm{C}$, depending on the species) may not be effective as forcing temperatures; this might also explain a reduced response rate. There are also good reasons that day length and photoperiod might prohibit a too early start of the growing season, even in very warm springs. The spring temperature level in Germany might still be too low to exhibit this missing non linearity at the warm end. In addition, the necessary winter chilling may not be completely fulfilled under warm spring conditions; thus, plants might need more forcing temperatures (Cannell \& Smith 1983), such that the temperature response at the warmer end may not be linear anymore.

However, even analysing the century-long records in our phenological data set comprising high inter annual variation in temperature does not display the suggested non-linearity of the response at both ends of the temperature range. The LOWESS smoothing only displayed a slight reduction of the response towards colder springs, which is especially valid for one station (Fig. 2, Villingen).

Furthermore, the use of local climate station data (Fig. 3) does not produce an overall s-shaped response. As the temperature response at the colder stations is lower (see Table 1), the overall local temperature response curve is flattened at the colder end. For the warmer climates, the local temperature in spring is obviously higher than the German average. Here, the response is very similar to that in other stations. There might exist the key problem that the earlier the onset dates (e.g. the end of March), the less suitable the 2 fixed temperatures of March and April.

Only in animal phenology have T. H. Sparks et al. (unpubl. data) found for 3 long-term records of mean first egg laying dates of pied flycatcher Ficedula hypoleuca in Wales $(46,26$, and $21 \mathrm{yr})$, which were remarkably synchronised and had identical temperature response rates, that one of the sites experienced an unexplained additional change in mean laying date 
(i.e. shift in the intercept on the $y$-axis). This could be due to adaptation to recent advanced spring conditions by a reduced interval between arrival and nesting, due to selection for earlier nesting individuals or caused by other influencing environmental conditions in the wintering grounds and on the migration route.

There are no other findings in the literature so far concerning altered temperature responses in plants over time. Our results also suggest that, despite some variations, there are no systematic differences in the temperature response rates in the first and second half of the last century. Minor, non-significant variations often reveal a smaller response in the second half of the century. However, for red currant only, there seems to be a systematic shift in average flowering dates (compared to mean March/April temperatures) towards later flowering dates in the second half of the 20th century. Any connection that this might have with a possible change in cultivars planted is speculative.

To summarise, our findings suggested a consistent basic linear relationship between onset dates of phenological phases and mean spring temperatures independent of different types of temperature data sets. Even century-long records comprising high inter annual variation in temperature did not display the hypothesized non-linearity of the temperature response at both ends of the temperature range. There was no evidence for systematic adaptation processes as the temperature response seemed to be mostly unaltered over the last century.

Acknowledgements. The authors thank the German Weather Service (DWD), especially Mrs. Chr. Polte-Rudolf, for providing phenological and climate data.

\section{LITERATURE CITED}

Cannell MGR, Smith RI (1983) Thermal time, chill days and prediction of budburst in Picea sitchensis. J Appl Ecol 20:951-963

Chmielewski FM, Rötzer T (2001) Response of phenology to climate change across Europe. Agric For Meteorol 108: 101-112

DWD (Deutscher Wetterdienst) (1949-1952) Deutsche Meteorologische Jahrbücher, US Zone 1945-1952. Deutscher Wetterdienst in der US-Zone, Zentralamt, Bad Kissingen

DWD (Deutscher Wetterdienst) $(1950,1951)$ Deutsches Meteorologische Jahrbuch, Britische Zone 1945-1948, Ergänzungsband sowie Deutsche Meteorlogische Jahrbücher, Britische Zone (1949-1950), Teil I-III. Meteorologisches Amt für Nordwestdeutschland, Hamburg

DWD (Deutscher Wetterdienst) (1960) Deutsches Meteorologisches Jahrbuch, Gebiet der ehemaligen französischen Besatzungszone 1945-1952. Deutscher Wetterdienst, Offenbach am Main

Ihne E (1883-1941) Beiträge zur Phänologie / Phänologische Beobachtungen / Phänologische Mitteilungen. Selbstverlag des Verfassers, Darmstadt

Editorial responsibility: Helmut Mayer, Freiburg, Germany
IPCC (Intergovernmental Panel on Climate Change) (2001) McCarthy JJ, Canziani OF, Leary NA, Dokken DJ, White KS (Eds) Climate Change 2001: Impacts, adaptation \& vulnerability. Contribution of Working Group II to the Third Assessment Report of the Intergovernmental Panel on Climate Change. Cambridge University Press, Cambridge

Matsumoto K, Ohta T, Irasawa M, Nakamura T (2003) Climate change and extension of the Ginkgo biloba L. growing season in Japan. Global Change Biol 9 (11):1634-1642

Menzel A (2003) Plant phenological anomalies in Germany and their relation to air temperature and NAO. Clim Change 57 (3):243-263

Menzel A, Testka AJ (2002) Beispiele phänologischer Reihen des 20. Jahrhunderts. Klimastatusbericht 2001 des Deutschen Wetterdienstes. Deutscher Wetterdienst, Offenbach am Main, p 58-66

Mitchell TD, Jones PD (2005) An improved method of constructing a database of monthly climate observations and associated high-resolution grids. Int $\mathrm{J}$ Climatol 25: 693-712

Mitchell TD, Carter TR, Jones PD, Hulme M, New M (2004) A comprehensive set of high-resolution grids of monthly climate for Europe and the globe: the observed record (1901-2000) and 16 scenarios (2001-2100). Tyndall Working Paper 55 (July 2004), Tyndall Centre, University of East Anglia, Norwich, p 1-30, also available at: www. tyndall.ac.uk/publications/working_papers/wp55.pdf

Parmesan C, Yohe G (2003) A globally coherent fingerprint of climate change impacts across natural systems. Nature 421:37-42

Peñuelas J, Filella I, Comas P (2002) Changed plant and animal life cycles from 1952 to 2000 in the Mediterranean region. Global Change Biol 8:531-544

Root TL, Price JT, Hall KR, Schneider SH, Rosenzweig C, Pounds JA (2003) Fingerprints of global warming on wild animals and plants. Nature 421:57-60

Schnelle F, Witterstein F (1952) Beiträge zur Phänologie Deutschlands II. Tabellen phänologischer Einzelwerte von etwa 500 Stationen der Jahre 1936-1944. Berichte des Deutschen Wetterdienstes in der US-Zone 1952. Deutscher Wetterdienst in der US-Zone, Bad Kissingen

Schönwiese CD, Walter A, Rapp J, Meyhöfer S, Denhard M (1998) Statistische Analyse der Klimavariabilität und anthropogene Klimasignale in globaler und regionaler Betrachtung. Berichte des Instituts für Meteorologie und Geophysik der Universität Frankfurt/Main, Nr. 102, Johann Wolfgang Goethe Universität, Frankfurt am Main

Seyfert F (1957, 1960, 1961) Phänologische Tabellen 1947-1956 aus dem Gebiet der Deutschen Demokratischen Republik. Abhandlungen des Meteorologischen und Hydrologischen Dienstes der Deutschen Demokratischen Republik, Nr. 37 , 50 und 57. Akademie-Verlag, Berlin

Sparks TH, Carey PD (1995) The response of species to climate over 2 centuries: an analysis of the Marsham phenological record, 1736-1947. J Ecol 83:321-329

Sparks TH, Menzel A (2002) Observed changes in seasons: an overview. Int J Climatol 22:1715-1725

Sparks TH, Jeffree EP, Jeffree CE (2000) An examination on the relationship between flowering times and temperature at the national scale using long-term phenological records from the UK. Int J Biometeorol 44:82-87

Walther GR (2004) Plants in a warmer world. Perspect Plant Ecol Evol Syst 6(3):169-185

Walther GR, Post E. Convey P, Menzel A and 5 others (2002) Ecological responses to recent climate change. Nature 416:389-395

Submitted: June 10, 2005; Accepted: September 28, 2005

Proofs received from author(s): November 10, 2005 